\title{
Corpus-based Study of Identifying Verb Patterns Used in Pakistani Newspaper Headlines
}

\author{
Muhammad Din \\ Dept. of English, The Islamia University of Bahawalpur, Pakistan \\ Mamuna Ghani \\ Dept. of English, Faculty of Arts \& Islamic Learning, The Islamia University of Bahawalpur, Pakistan
}

\begin{abstract}
Newspaper headlines are an important subgenre of media genre and enjoy much significance in news discourse. Headlines are ascribed different functions as they are the opening section to their respective text. This corpus-driven study strives to identify those verb patterns which have been used in Pakistani newspaper headlines. To identify different verb patterns used in newspaper headlines, the researcher compiled a corpus of 3135 newspaper headlines consisting of 28646 words drawn from three on-line Pakistani English newspapers which include The Dawn, The Nation and The News. The researcher tagged this corpus by using the software TagAnt and analyzed this corpus with the help of corpus tool AntConc to identify the verb patterns used in these Pakistani English newspaper headlines. To this end, the researcher analyzed the compiled corpus in accordance with the POS Tags given by Tree Tagger Tag Set. This study has found different verb patterns which have been used in newspaper headlines.
\end{abstract}

Index Terms—newspaper headlines, verb patterns, news discourse, corpus, language description

\section{INTRODUCTION}

Newspaper headlines are an important subgenre of media genre and enjoy much significance in news discourse. Headlines are ascribed different functions as they are the opening section to their respective text. Arousing readers' curiosity, encapsulating the content of a story and monitoring readers' perception, attention and reading process are those salient features which mark newspaper headlines.

The term pattern refers to an approach to language description which involves the prioritizing of lexical items in a language and their grammatical dependencies (Hunston \& Francis 1998, 1999; Francis et al. 1996; Francis 1993). According to Mason and Hunston (2004), patterns means sequence of elements in which each element comprises of a word class, group, lexical item or clause.

\section{A. Characteristics of Headlines of English Newspapers}

A newspaper headline gives reader an overall picture of news whereas newspaper headline writers use different stylistic devices to attract readers' attention. Swan (1995) styles newspaper headlines as short titles which are written in a special style. Reah (1998) maintains that headlines render a variety of functions owing to their being unique kind of texts and they enjoy specific shape, structure and content. The sensational style of headlines arouses readers' curiosity.

\section{B. Language Features of Newspaper Headlines}

The use of lexical items is one of the major language features of newspaper headlines. According to Morley (1998), the vocabulary of headlines can be unusual, sensational and short. A special register is also another feature of the language used in headlines. Hakobian and Krunkyan (2009) claim that different stylistic phonetic devices like alliteration, rhythm, rhyme, parallel constructions and antithesis render the newspaper headlines more expressive. These researchers also claim that headline writers also use some lexical stylistic devices like metaphor, metonymy, simile, allusion and various kinds of epithets. McArthur (1992) maintains that the language of headlines is affected by constraints on space. While discussing the layout and punctuation of newspaper headlines, McArthur (1992) claims that many newspapers have sedate and largely lower-case styles. The punctuation is exploited in special conventions. For instance, the sign of exclamation is used to generate interest, the question mark implies speculation or doubt and comma is used for "and". The conventional punctuation marks are sometimes ignored. For example, the use of quotation marks characterizes such allegations or statements which newspaper intends to distance itself. So far as the style and syntax of newspaper headlines are concerned, McArthur (1992) claims that quality press tends to use high register and less emotive words to be relatively sober and restrained whereas the tabloids prefer to use colloquial and pejorative language. Present-day usage is marked with concentrated sequences which string terms together and these strings entail heavy pre-modification. McArthur (1992) has also thrown light on some more features of the language of newspaper headlines like strange combinations and unintended relations, ambiguity, word-play, allusions and mixed metaphors.

\section{Verb Patterns}


Of the words of all classes, verbs can be described most comprehensively. The possible complementation of a verb is characterized by verb patterns. This approach to the grammar of verbs is different from the functional analysis to identify subject, object, complement clause element (e.g. Karrlson et al. 1995; Quirk et al. 1996) or participant role or case (Halliday 1994; Fillmore 1969). Mason and Hunston (2004) have described some verb patterns in three groups. The first group comprises of the patterns which include a clause element. For instance, these verb patterns are given as follows;

- $\quad$ verb + that clause and

- $\quad$ verb + noun group + wh-clause

The second group consists of the patterns which include one or more group or word class elements. These patterns have been given as follows;

- verb + noun group,

- $\quad$ verb + noun group + adjective/adjective group and

- $\quad$ verb + adverb

The third group of verb patterns consists of one or more specific lexical items. The instances of these patterns have given as follows;

- $\quad$ verb + as + noun group and

- $\quad$ verb + possessive + way + prepositional phrase or adverb.

\section{Research Objective of the Study}

The research objective of this study has been given as follows;

$>$ To identify the verb patterns used in Pakistani English newspaper headlines.

\section{E. Research Question of the Study}

The research question of this study has been given as follows;

$>$ What are verb patterns used in Pakistani English newspaper headlines?

\section{LITERATURE REVIEW}

Mason and Hunston (2004) have conducted a study to recognize verb patterns. To this end, these researchers have used 100 instances of the verb 'decide' from the Bank of English Corpus. This study has taken the patterns of the chosen verb from Sinclair et al. (1995) and also taken a linear instead of hierarchical approach to the patterns of the selected verb. Moe (2014) has conducted a study to analyze the language of newspaper headlines of the daily English newspaper "The New Light of Myanmar". The researcher has collected 31 newspapers to analyze them thoroughly. This study has examined the language used in headlines at graphic, graphological, grammatical, semantic and lexical levels.

Alireza and Samuel (2012) have explored the rhetorical and textual strategies employed by two newspapers in their editorial headlines to propagate their vested ideologies. The researchers have used 40 editorial headlines from two English newspapers i.e. Tehran Times and New York Times. The results of this analyses carried out in this study reveal that these two newspapers have employed existential, interactive verb and nominalization as different kinds of presupposition. Moreover, these researchers maintain that the writers of the editorials published in these papers have also employed some rhetorical devises which include parallelism, alliteration, metonymy, pun, testimonials, quotations, allusions, neologism, antithesis and irony. Klavans and Kan (2015) claim that meaningful insight into the content and type of an article can be reached by comprehending the distribution and occurence of verbs. These researchers also believe that the analysis of verbs in a document can lead to the understanding of the conceptual map of actions and events in a document. Verbs can also help in the categorization of articles into different genres. As Biber (1989) classifies verbs into three classes of private, public and suasive.

Develotte and Rechniewski (2001) have analyzed newspaper headlines to address how headlines acquire prominence through diffusion, orient readers' interpretation and share cultural context evoked by them. This study has also identified those typical linguistic features which are used in newspaper headlines for the analysis of national representation. This study has analyzed the linguistic features of designation, appraisal and presupposition. To this end, the researchers have constituted a corpus comprising of the headlines of Australian and French newspapers. Develotte and Rechniewski (2001) claim that headlines deliberately seek impact using alliteration, puns, emotive vocabulary and rhetorical devices. Headlines also act as such signposts that highlight the route that leads the readers not only to the content of a story but also the orientation which is essential for the understanding of an article. This study has found that Australian and French corpus have made use of designation along with two other processes i.e. generalization and personification. This study also reports that newspaper headlines resort to the use of appraisal and its different forms to reinforce allusions. In the same vein, these headlines also employ the linguistic feature of presupposition particularly linguistic presupposition which is derived from syntactic structure and from anaphoric or cataphoric use and pragmatic presupposition. Znamenskaya (2005) classifies the lexical and syntactical variation found in newspaper headlines. 
According to her, the omission of articles, verbs and auxiliary verbs, nominalization, use of complex noun phrases, use of short words and the use of puns are such language features which mark newspaper headlines.

Mouzuaityte (2015) has analyzed British newspaper headlines to overview newspaper style, analyze language features of newspaper headlines and indicate the frequency of those stylistic features which are used in newspaper headlines. The researcher has used descriptive statistic and descriptive theoretical analysis as the research methods. According to the findings of this study, the omission of articles, relative pronouns, determiners, verbs and auxiliaries and titles is one of the salient features of newspaper headlines. This study also reports that the headlines writers also make use of short words, loan words, nominalization and noun phrases to make them more eye-catching and attractive. According to Mouzuaityte (2015), the use of certain linguistic strategies and gimmicks also characterize English newspaper headlines. Khamahani (2015) has carried out a study to investigate the lexical density in the headlines of Tehran Times and Azeri News. To this end, the researcher has collected 200 headlines from these two newspapers. This study has analyzed grammatical pre-modification which includes the use of deictic and post deictic. But this study has chiefly focused on the analysis of lexical density found in the selected newspaper headlines. This study reports that Azeri News headlines have higher lexical density than Tehran Times. The researcher has also found that there is a remarkable use of content words in Azeri News headlines. This study also reports that there is lexical density in nominal groups which are chiefly pre-modified. Bonyadi and Samuel (2013) have carried out a contrastive study to analyze the headlines of newspaper editorials. The researchers have collected 40 editorial headlines from the electronic versions of two English newspapers i.e. Tehran Times (TT) and New York Times (NYT). This study has analyzed the headlines of the selected editorials in terms of rhetorical devices and linguistic device of presupposition. The researchers have classified the selected headlines into two categories of verbal and nonverbal for their textual analysis. According to the findings of this study, there are $75 \%$ of New York Times headlines which belonged to nonverbal category whereas $25 \%$ of them belonged to verbal category. On the other hand, of Tehran Times headlines $60 \%$ were verbal type and $40 \%$ were nonverbal. This study also reports that editorial headline writers make use of parallelism, alliteration, testimonial, metonymy, pun, irony, quotation out of context, allusion, neologism and antithesis as rhetorical devices. So far as the use of presupposition is concerned, the researchers maintain that both the papers make use of existential and lexical presuppositions for the persuasion purposes equally. Weir and Anagnostou (?) have conducted a case study in corpus analysis to explore newspapers. The data for this corpus analysis comprises of the text content of a single file of 32,070 articles from a leading Scottish daily newspaper. The analysis conducted in this study consists in the dimensions of identifying a set of top ten terms in different categories, extracting insight on gender specific terms in the compiled corpus and contrasting characteristics of the compiled newspaper corpus and reference corpus i.e. the British National Corpus (BNC). Dazdarevic et al. (2015) have conducted a study on using corpus in enhancing reporting verb patterns in teaching and learning process. According to Dazdarevic et al. (2015), corpus approach is such an excellent linguisitic tool which has opened up a new world language patterns. Corpus-based teaching of grammar has proved an essential tool as it presents different grammar structures and language variations. The study has analyzed different patterns in which the verbs like 'promise', 'advise' and 'deny' have been used. According to the findings of this study, the verb promise has been used in two 'patterns' i.e. "verb + infinitive" and "verb + ConSub". Of these two patterns, the formar pattern is mostly used for spoken section and the latter pattern is used for written section. So far as the patterns for the verb 'advise' are concerned, the study reports that there are five patterns in which this verb has been used. These patterns include 'advise + ing', 'advise + ConSub', 'advise + base form of verb', 'advise + modal' and 'advise + do'.

\section{METHODOLOGY}

To identify different verb patterns used in newspaper headlines, the researcher compiled a corpus of 3135 newspaper headlines consisting of 28646 words drawn from three on-line Pakistani English newspapers which include The Dawn, The Nation and The News. The researcher tagged this corpus by using the software TagAnt and analyzed this corpus with the help of corpus tool AntConc to identify the verb patterns used in these Pakistani English newspaper headlines. To this end, the researcher analyzed the compiled corpus in accordance with the POS Tags given by Tree Tagger Tag Set which was adopted from: https://courses.washington.edu/hypertxt/csar-v02/penntable.html. The identified verb patterns have been presented in the section of the findings of this study.

\section{RESULTS AND DISCUSSION}

This study has analyzed the compiled corpus with help of corpus tool AntConc and found different patterns of verbs which have been used in the Pakistani English newspaper headlines. The verbs which have been analyzed to identify their patterns include the verb "be" (is, was, were, being), "have" (has, having) and the present $3^{\text {rd }}$ person singular, present, past, past participle and present participle forms of verb. These identified verb patterns have been given as follows;

\section{A. Patterns of Verb 'Be'}


This study has found that the verb 'be' along with its different forms i.e. 'to be', 'was', 'were', and 'being' has been used in different patterns. These patterns have been discussed as follows;

\section{Patterns of Verb 'Be'}

There are two types of patterns in which the verb 'be' has been used. They are given as follows;

1) noun + to be + past participle/adjective

2) noun + modal + be + noun/past participle/adjective

3) noun + be + past participle

These patterns have been illustrated with the help of the figures 1, 2, and 3 given as follows;

_IN province_NN 15_CD varsities_NNS to_TO be_VB accorded_VVN elite_JJ status_NN Two_CD killed_

chief_NN wants_VVZ Zardari_NP to_TO be_VB admitted_VVN to_TO hospital_NN Walking_VVG on_

Fawad_NP urges_VVZ world_NN to_TO be_VB alive_JJ to_TO perilous_JJ situation_NN Rs300

Figure 1: Screenshot of patterns of verb 'be' (to + be)

accidents_NNS Traffic_NN police_NN will_MD be_VB complainant_NN if_IN victim_NN _." s_NN heirs_

for_IN Sikh_JJ pilgrims_NNS will_MD be_VB completed_VVN by_IN Sept_NP 30_CD Polio_NP

US_NP , _, France_NP , B, Britain_NP may_MD be_VB complicit_JJ in_IN Yemen_NP war_NN crimes_

Figure 2: Screen shot of patterns of verb 'be' (modal + be)

_" hell_NN “"

Figure 3: Screenshot of patterns verb 'be' (noun + be + past participle)

\section{Patterns of Verb 'Was/Were'}

The past forms of the verb 'be' (was/were) have used as main and auxiliary verb in the verb patterns used in the newspaper headlines as follows;

I. noun + was + noun

II. noun + was $($ modal $)+$ past participle + noun

III. noun + were (modal) + past participle + cardinal number + noun

The following figure illustrates these verb patterns used in newspaper headlines.

verify_VV import_NN documents_NNS India_NP was_VBD a_DT miracle_NN democracy_NN ._SENT But_CC Repatriated_VVN Lahore_NP ACs_NP judges_NNS were_VBD appointed_VVN 70_CD days_NNS back_RB Province of_IN Ukraine_NP phone_NN call_NN was_VBD Biden_NP Tens_NNS of_IN thousands_NNS march_

Figure 4: Screenshot of patterns of verb 'was/were'

\section{Patterns of Verb 'being'}

This study has found that the verb 'being' has been used as main (lexical) verb in different newspaper headlines. It has also been found that this verb is not preceded by any auxiliary verb. This pattern also implies the passive structure of those newspaper headlines in it has been used. This pattern is given as follows;

noun + being + past participle

The following screenshot of the newspaper headlines illustrates this pattern.

SC_NP to_TO gain_NN funds_NNS being_VBG deposited_VVN by_IN Bahria_NP Town_NP Agbegne
urban_JJ context_NN Medical_JJ waste_NN being_VBG dumped_VVN around_IN Abbasi_NP Shaheed_NP Hosp
of_IN flats_NNS for_IN workers_NNS being_VBG ensured_VVN ,_s says_VVZ Ghani_NP Murad_NP ur
Establishment_NP Division_NP Deadlines_NNS being_VBG extended_VVN as_IN NCC_NP meets_VVZ tomorrow_
:_: minister_NN Court_NN orders_NNS not_RB being_VBG followed_VVN in_IN Zardari_NP case_NN :_: lawy

Figure 5: Screenshot of patterns of verb 'be' (being)

\section{B. Patterns of Verb 'Have'}

According to the findings of this study, the verb 'have' has been used as main, auxiliary and causative verb in newspaper headlines. These verb patterns have been given as follows;

I. to + have + noun + past participle

II. modal + have + noun + present participle

III. modal + have + noun

The following screenshot explains these three patterns of verb 'have'. 


detained for refusing to have children vaccinated Govt considering
Civil Defense, police may have difficulty meeting Muharram security
wife`IUB students will have internship facility at civil

Figure 6: Screenshot of patterns of verb 'have'

\section{Patterns of Present $3^{\text {rd }}$ Person Singular Verb}

This study has found that the most frequent pattern which appears in newspaper headlines comprises of the present $3^{\text {rd }}$ person singular verb. There are 1225 concordance hits of this pattern used in the newspaper headlines. It has also been noted that this pattern is used to describe the actions of past as well as those of future. Mostly this form of verb is preceded by a noun or noun phrase but followed by different parts of speech. The structure of this pattern consisting of the present $3^{\text {rd }}$ person singular form of verb has been given as follows;

noun + present $3^{\text {rd }}$ person singular verb

According to the findings of this study, this pattern (noun + present $3^{\text {rd }}$ person singular verb) is followed by different patterns like adjective, adverb, base form of verb, cardinal number, determiner, infinitive, particle, past form of verb, past participle, personal pronoun, plural noun, preposition, present participle, gerund, proper noun, proper noun plural, singular noun, wh- adverb (how) and wh-pronoun (what/who). The following figure 7 illustrates some of the patterns in the which the present $3^{\text {rd }}$ person singular form of verb has been used.

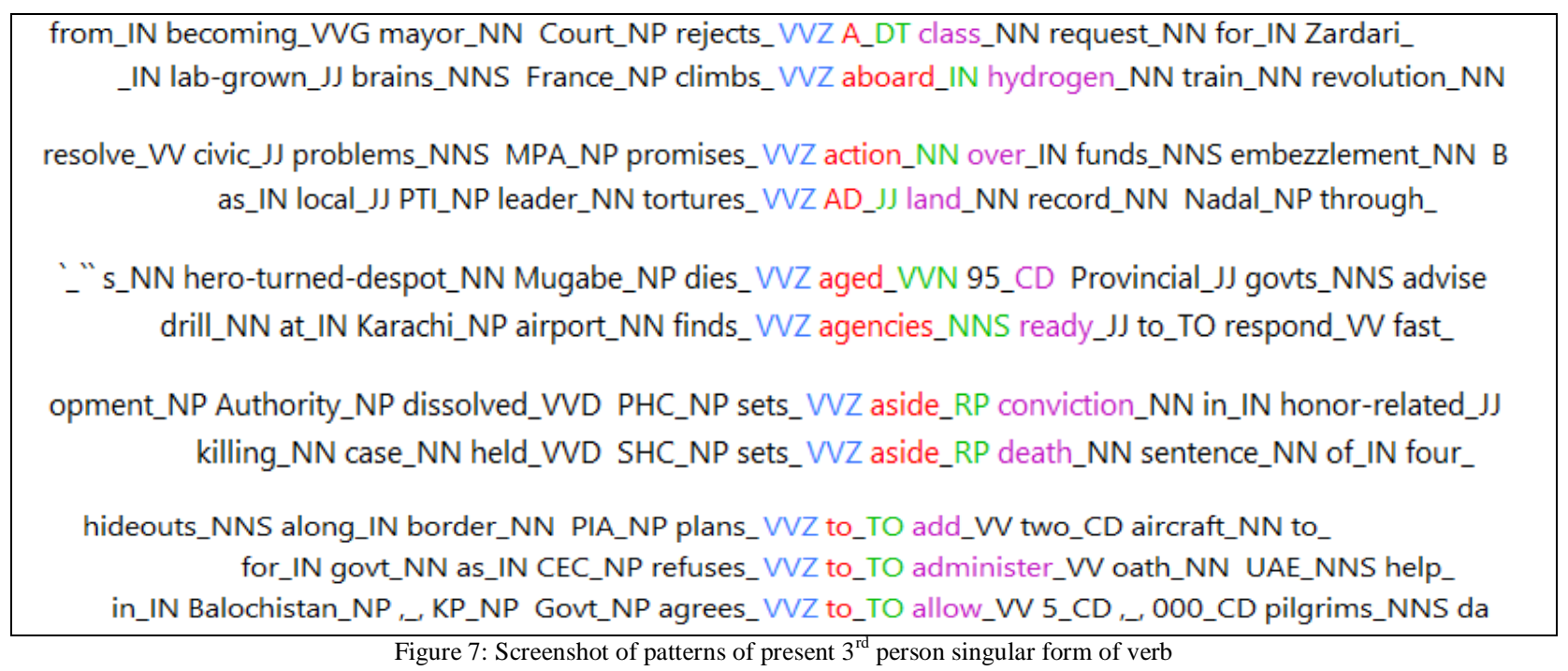

\section{Patterns of Present Form of Verb}

The present study has found the following verb patterns in which the present form of verb has been used in newspaper headlines.

I. noun + to + present form of verb

II. wh - adverb + to + present form of verb

III. past participle + to + present form of verb

IV. present non $-3^{\text {rd }}$ person singular + to + present form of verb

V. modal + to + present form of verb

VI. present participle/gerund + to + present form of verb

VII. past tense $(\mathrm{V} 2)+$ to + present form of verb

VIII. adjective + to + present form of verb

In all the above given patterns, the present form of verb is followed by different patterns like adjective, adverb, base form of verb, determiner, particle, past participle, personal pronoun, plural noun, preposition, present participle/gerund, proper noun, singular noun, and wh-pronoun (what/who). The following figure 8 illustrates some of the patterns in the which the present form of verb has been used. 
option_NN but?_NN :_: India_NP to_TO get_VV a_DT befitting_VVG response_NN if_IN imposed its_PP\$ credentials_NNS They_PP can_MD file_VV a_DT charge_NN posthumously_RB against_IN Jawah Zardari_NP knows_VVZ how_WRB to_TO control_WV a_DT puppet_NN PM_NP Indian_JJ army_

_WVD to_TO make_VV anti-polio_NP drive_WV a_DT success_NN in_IN tribal_J districts_ child_NN safety_NN needed_VVN to_TO stop_WV abuse_NN , moot_NN told_VVD Good_J parentin drug_NN maker_NN ordered_VVD to_TO review_WV accounts_NNS Istanbul_NP opposition_NN leader_ Oghi_NP Govt_NP fails_VVZ to_TO take_VV action_NN against_IN flawed_J appointments_NNS notice_NN for_IN failing_VVG to_TO look_WV after_IN Marghazar_NP Zoo_NP Tug_NN of_ award_NN Tottenham_NP throw_VVP away_RB lead_WV against_IN Arsenal_NP, „, unease_NN persists_VV shrink_VV 26pc_J Traders_NNS to_TO protest_VV against_IN CNIC_J J condition_NN on_IN Oct_ drive_NN continues_VVZ Traders_NNS to_TO protest_VV against_IN CNIC_J condition_NN on_IN Oct_ House_NP Army_NP ready_J to_TO thwart_VV any_DT Indian_J misadventure_NN Karachi_NP '_ _NP hasn $>$ t_NP agreed_VVD to_TO return_VV any_DT money_NN Pakistan_NP to_TO continue_ mark_NN No_DT plan_NN to_TO privatize_VV any_DT Punjab_NP hospital_NN :_: minister_NN P

Figure 8: Screenshot of patterns of present form of verb

\section{E. Patterns of Past Form of Verb}

The patterns in which the past of verbs has used in Pakistani newspaper headlines have been given as follows; noun +past form of verb noun + wh-pronoun + past form of verb noun + wh-determiner + past form of verb noun + adverb + past form of verb

This study has found that in all the patterns given above the past form of verb is followed by different patterns like adjective, adverb, base form of verb, determiner, particle, past participle, personal pronoun, plural noun, preposition, present participle/gerund, proper noun, singular noun, cardinal number and infinitive. The following figure 9 illustrates some of the patterns in the which the present form of verb has been used.

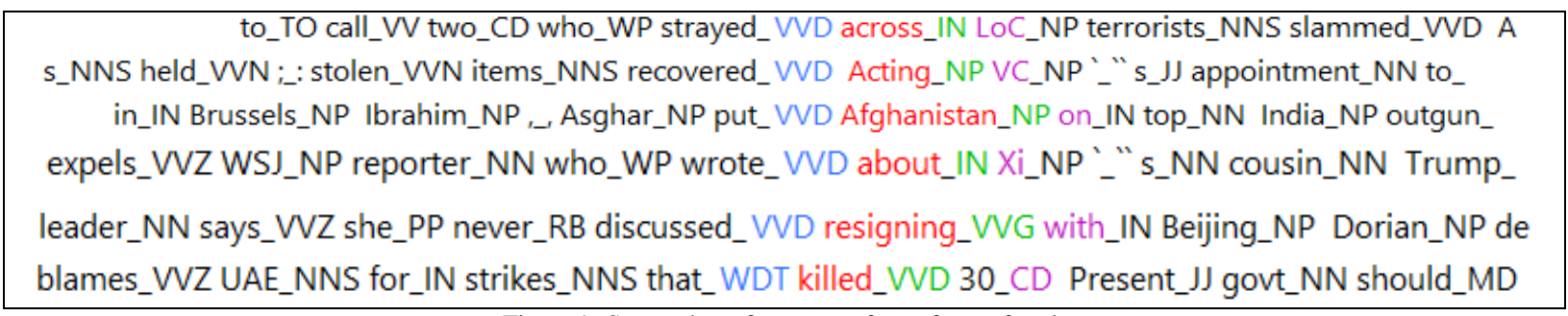

Figure 9: Screenshot of patterns of past form of verb

\section{F. Patterns of Past Participle Form of Verb}

The past participle form of verb has been used in newspaper headlines in the patterns given as follows;

I. noun + past participle

II. noun + auxiliary verb + past participle

III. noun + infinitive + past participle

IV. noun + adverb + past participle

V. noun + present participle + past participle

VI. noun + present form of verb + past participle

VII. noun + past form of verb + past participle

VIII. noun + cardinal number + past participle

According to the findings of this study, this pattern (noun + past participle form of verb) is followed by different patterns like adjective, adverb, cardinal number, infinitive, particle, noun (singular/plural), preposition and conjunction. The following figure 10 illustrates some of the patterns in the which the past participle form of verb has been used. 


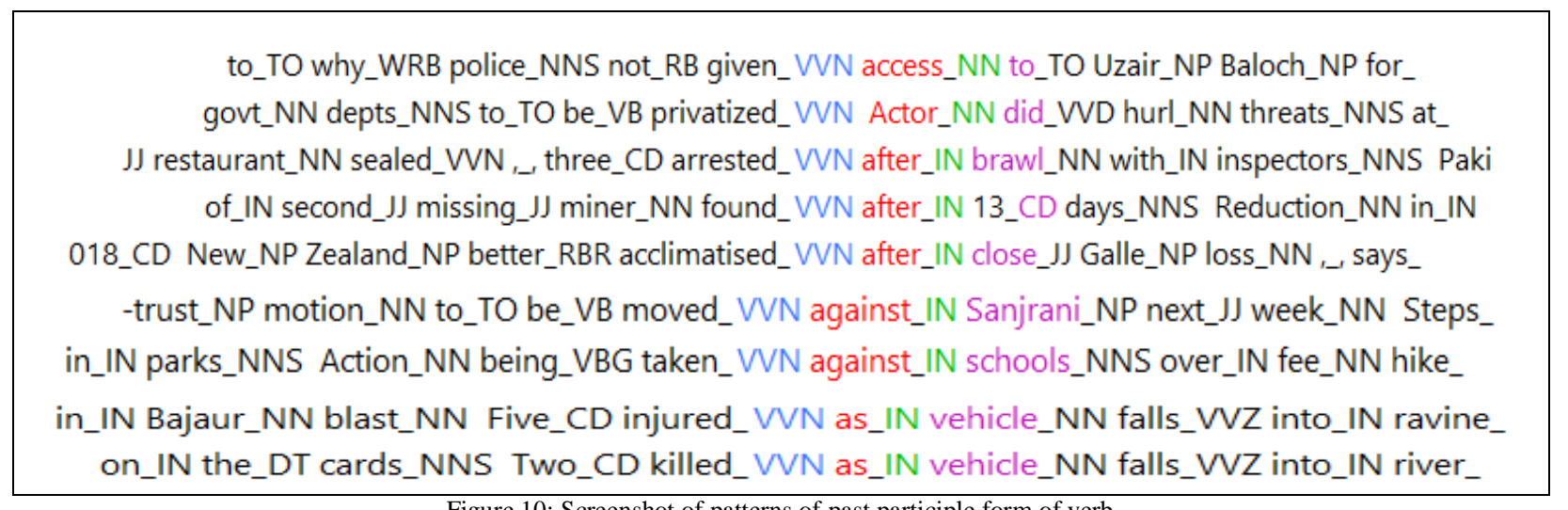

Figure 10: Screenshot of patterns of past participle form of verb

\section{G. Patterns of Present Participle Form of Verb}

The present participle form of verb has been used in newspaper headlines in the patterns which have been given below;

I. noun + present participle

II. noun + preposition + present participle

III. noun + present form (base form) + present participle

IV. noun + auxiliary verb + present participle

V. infinitive + preposition + present participle

VI. noun + adjective + present participle

VI. noun + adverb + present participle

The present study has also found that the verb patterns of present participle form of verb given above are followed by different patterns like adjective, adverb, determiner, noun, particle, past participle, cardinal number and infinitive. The following figure 11 illustrates some of the patterns in the which the present participle form of verb has been used.

\section{CONCLUSION}

This corpus-based study has strived to identify those verb patterns which have been used in Pakistani newspaper headlines. This study has identified different patterns in which verbs have been used. This study has identified that Pakistani newwpaper headlines have mostly used base form of verb for present, past and future actions. Apart from this, it has also been found that present participle form of verb without any auxiliary verb has been used in the analyzed headlines.

\section{REFERENCES}

[1] Alireza, B. \& Samuel, M. (2012). Headlines in newspaper editorials: A contrastive study. International Research Journal of Social Sciences, 1 (3), pp. 1-7.

[2] Biber, D. (1989). A typology of English texts. Language, 27, pp.3-43.

[3] Bonyadi, A. \& Samuel, M. (2013). Headlines in newspapers: a contrastive study. SAGE Open, April-June 2013: 1-10.

[4] Dazdarevic, S., Fijuljanin, F. \& Rastic, A. (2015). Using corpus in enhancing reporting verb patterns in teaching/learning process. Journal of Transdisciplinary Studies, 8 (2), pp.131-142.

[5] Develotte, C. \& Rechniewski, E. (2001). Discourse analysis of newspaper headlines: A methodological framework for research into national representation. Retreived from: https://www.researchgate.net/publication/316282294, pp.1-17.

[6] Fillmore, C. J. (1969). Toward a Modern Theory of Case. In D. A. Reibel \& S. A Shane (Eds.), Modern Studies in English, pp. 361-375, New Jersey: Prentice Hall.

[7] Francis, G. (1993). A Corpus-driven Approach to Grammar: Principles, Methods and Examples. In M. Baker et al. (Eds.), Text and Technology, pp. 137-156. Amsterdam: Benjamins.

[8] Francis, G., Hunston, S. \& Manning E. (1996). Collins Cobuild Grammar Patterns 1: Verbs. London: HarperCollins.

[9] Hakobian, L., and Krunkyan, K. (2009). Newspaper Headlines. A Handbook. Yerevan Anania Shirakatsill University of International Relations

[10] Halliday, M. A. K. (1994). An Introduction to Functional Grammar. 2nd edition. London: Arnold.

[11] Hunston, S., \& Francis, G. (1998). Verbs observed: A corpus-driven pedagogic grammar. Applied Linguistics, 19 , 45-72.

[12] Hunston, S., \& Francis, G. (1999). Pattern Grammar: A corpus-driven approach to the lexical grammar of English. Amsterdam: Benjamins.

[13] Karlsson, F., Voutilainen, A., Heikkilä, J. \& Anttila, A. (Eds.). (1995). Constraint Grammar: A language-independent system for parsing unrestricted text. Berlin: Mouton de Gruyter.

[14] Khamahani, G. (2015). A corpus-based analysis of Tehran Times and Azeri News headlines: Focus on lexical density and readability. International Journal of Humanities Social Sciences and Education (IJHSSE), 2 (1), 2015, pp. 12-16. 
[15] Mason and Hunston. (2004). The automatic recognition of verb patterns: A feasibility study. International Journal of Corpus Linguistics, 9 (2), pp. 253-270.

[16] McArthur, T. (1992). The Oxford companion to the English language. Oxford University Press. New York

[17] Morley, J., (1998). Truth to Tell: Form and Function in Newspaper Headlines. CLUEB.

[18] Moe, S. (2014). A brief study of the language of newspaper headlines used in "The New Light of Myanmar". Hinthada University Research Journal, 5 (1), pp. 82-92.

[19] Mozuraityte, R. (2015). Newspaper style: Stylistic features of headlines. Bachelor Thesis, Siauliai, 2015.

[20] Quirk, R., Greenbaum, S., Leech, G. \& Svartvik, J. (1985). A Comprehensive Grammar of the English Language. London: Longman.

[21] Reah, D., (1998). The Language of Newspapers. Routledge. London \& New York.

[22] Swan, M., (1995). Practical English Usage. Oxford University Press.New York.

[23] Weir, G. R. S. \& Anagnostou, N. K. (2007). Exploring newspapers: a case study in corpus analysis. In: ICTATLL Worksop 2007, 2007-08-01 - 2007-08-02.

[24] Znamenskaya, T. A., (2005). Stylistics of the English Language. Moscow: Kom Kniga.

Muhammad Din is an Assistant Professor of English at Government Postgraduate Collegge Burewala, Pakistan. He holds the degree of M. Phil (Linguistics) and is a PhD scholar at The Islamia University of Bahawalpur, Pakistan. His research interests cover teaching English as foreign language through literature, corpus linguistics and critical thinking.

Mauna Ghai is a Professor of Linguistics and Dean of the faculty of Arts and Management Sciences in The Islamia University of Bahawalpur, Pakistan. She holds the degree of $\mathrm{PhD}$ in Applied Linguistics from UK. She has special interest in motivation. She has produced more than $50 \mathrm{PhD}$ scholars and hundreds of $\mathrm{M}$. Phil scholars. 